Exploring the feasibility of a classroom-based vocabulary intervention for mainstream secondary school students with language disorder

Hilary Lowe

Victoria Joffe

School of Health Sciences

City, University of London

Northampton Square

London, EC1V 0HB, UK

Corresponding author Hilary Lowe Hilary.Lowe@city.ac.uk 


\title{
Exploring the feasibility of a classroom-based vocabulary intervention for mainstream secondary school students with language disorder
}

\begin{abstract}
Vocabulary knowledge has been shown to be a predictor of academic success, posing a challenge for children and young people with language disorder. Language disorder can persist into adolescence and yet there is limited evidence on how to support the vocabulary skills of adolescents with language disorder in a mainstream setting. This article describes an experimental study aimed at investigating the feasibility of a wholeclass approach, to increase the understanding and use of curriculum vocabulary, in adolescents with language disorder.

Ten curriculum words were taught by the science teacher using a phonological-semantic approach, and 10 matched same-topic words were taught using routine teaching practice. Progress was made post-intervention in word knowledge of both lowfrequency experimental and control words, with significantly greater change in knowledge of the experimental words. Most students, and the teacher, viewed the phonological-semantic word-learning approach favourably.
\end{abstract}

Key Words: adolescents; language disorder; vocabulary; classroom-based intervention; collaborative practice 


\section{Introduction}

Vocabulary knowledge and academic attainment

Around $10 \%$ of all children have language disorder either as their primary area of need, or in association with another condition such as a learning or medical need (Norbury, Gooch, et al. 2016), and this can persist into adolescence and beyond (Johnson, Beitchman, and Brownlie, 2010). This paper uses the term language disorder as a generic term to include those who have a language impairment as their primary need, as well as those whose language difficulties occur in association with a learning difficulty, medical condition, or social disadvantage (Bishop et al., 2016). Thus, it is common to find approximately two pupils in every mixed ability class experiencing language difficulties sufficient to impede access to the curriculum.

Language disorder persisting beyond the age of 5:6 is associated with lower literacy levels and poorer academic achievement at age 16-17 (Snowling, Adams, Bishop, and Stothard, 2001). Acquiring new vocabulary poses a particular challenge for children with language disorder (McGregor et al., 2013), placing them at risk for academic failure: vocabulary knowledge has been shown to be a predictor of reading outcomes (Snowling, Muter, and Carroll, 2007) and 16+ examinations (Croll, 1995). In the longer term, language disorder continues to have an impact on educational attainment, cognition, behaviour, occupational levels, and social and emotional functioning well into adulthood (Clegg, Hollis, Mawhood, and Rutter, 2005).

\section{Phonological and semantic approaches to word learning}

The speed of word learning continues apace throughout secondary school (Ehren, 2002). It is estimated that between 6 and 17 years of age, typically developing children acquire 3000 words per year (Clark, 1995). This equates to 8 or 9 new words a day. This places the adolescent with language disorder at some disadvantage. During the 
school years, children encounter new words of increasing complexity and abstractness. The way in which children learn new words changes over time: as typically-developing children get older, they are more likely to acquire new words through contextual abstraction rather than direct teaching (Nippold, 2007), but children with language disorder are less likely to be able to learn new vocabulary in this way (Cain, Oakhill, and Lemmon, 2004).

Word knowledge is multi-faceted: for children to gain knowledge about words, a network of connections needs to be built up; semantic, grammatical, and phonological (Leonard, 1998). In order to learn the meaning of a word, children need to identify a recurring phonological form from the stream of speech, and map that phonological form onto the meaning of the word (Bishop, 1997). In order to use a word expressively, children need to retrieve the phonological form that they have previously mapped onto the meaning of that word, and access the motor program required to produce the word. Phonological information about a word can be stored according to its initial sound, its syllable structure, and how it rhymes with other words. Semantics explores the meaning of a concept, with semantic information being organised according to properties such as function, location, and attribute, and category. For example, evaporation begins with e, has 5 syllables, and rhymes with station (phonological information); and evaporation means when liquid turns into gas (semantic information). The nature of children's vocabulary difficulties may be related to a deficit in semantic representations, or phonological representations, or both (Lahey and Edwards, 1999).

The literature typically recommends a semantic approach to teaching vocabulary (e.g. Beck et al., 2002), yet for children with language disorder, the evidence suggests that a phonological element embedded in a semantic approach may improve the storage of accurate phonological representations of the word and hence provide a strong 
connection between word form and word meaning (Easton, Sheach, and Easton, 1997; Parsons, Law and Gascoigne, 2005; Ebbels et al., 2012; Joffe, Rixon, Hirani, and Hulme, forthcoming; St John and Vance, 2014; Wilson et al., 2015). With the adolescent age group, Joffe and colleagues conducted a randomised control trial with 357 12-year-old children with language disorder, providing vocabulary instruction based on developing semantic and phonological connections. The children who received the vocabulary intervention showed greater improvements on non-standardised expressive vocabulary measures, compared to a control group. Murphy et al. (2016) has shown that an adapted version of the programme used in Joffe et al. (forthcoming) - the Vocabulary Enrichment Programme (Joffe, 2011) - can be implemented as a wholeclass intervention; however, the intervention was delivered as a discrete programme rather than embedded within the delivery of the curriculum. One study has integrated phonological-semantic intervention into the curriculum, but with primary- aged children. Boland (2009) studied 11 children with language disorder aged 8:10 to 10:6 in mainstream primary schools. Ten teachers used a phonological-semantic approach to pre-teach three new science words at the beginning of one lesson. Progress was compared with three further science words which were given an equal amount of exposure during the lesson but were not pre-taught. As a group, the children with language disorder made significant overall gains in word knowledge for pre-taught over non pre-taught words. These results are encouraging and need replication with the secondary school age group.

\section{A universal model of intervention delivery}

The use of a whole-class approach in direct vocabulary instruction may be especially pertinent to the mainstream secondary school setting. The timetabling of individual focussed support time for one-to-one intervention in secondary schools is a challenge 
(Ehren, 2002). In addition, remaining in the classroom rather than being withdrawn for individual tuition is preferable for many children: Klingner et al. (1998) found that $37.5 \%$ of a cohort of 32 children aged $9-11$ years with specific learning disability preferred an inclusive model of support. This percentage may be even higher during the teenage years, when peer acceptance becomes of paramount importance (Whitmire, 2000).

There is an increased awareness of the need for direct vocabulary instruction in secondary schools. In the UK, for example, the Secondary National Curriculum (DfE, 2014) contains an explicit requirement for teachers to develop pupils' vocabulary actively. Studies which have examined vocabulary instruction at a universal level in the context of social disadvantage, e.g. Lawrence et al. (2012), and second language learning, e.g. Lesaux et al. (2014), have shown the potential of explicit vocabulary instruction using a semantic approach. Starling et al. (2012), implementing a whole school training programme in two secondary schools, showed that training teachers to modify their oral and written language, including vocabulary instruction, led to significant improvements in listening comprehension and written expression in adolescents with language disorder, showing that collaborative working between teachers and speech and language therapists can positively influence teachers' language in the classroom, and that this change in practice can impact favourably on student performance.

\section{Summary}

There is a need for explicit vocabulary instruction in schools, and robust teaching of new vocabulary is particularly important for children with language disorder, who are less able to absorb meanings of new words through contextual abstraction. Direct phonological instruction may be of benefit, especially for children whose vocabulary 
difficulty has a phonological component. Whilst research has indicated that combined phonological-semantic intervention can be effective, to our knowledge, there is no vocabulary intervention study which investigates a phonological-semantic approach embedded within the delivery of the mainstream secondary curriculum.

The current study therefore aims to address the following research questions: (1) Can phonological-semantic word-learning activities be implemented in a whole-class approach to vocabulary teaching within the mainstream secondary school curriculum? (2) What are the views of the teacher, and of young people with language disorder, on the use of a whole-class phonological-semantic approach to vocabulary teaching? The following hypothesis is proposed: increase in word knowledge for words taught through phonological-semantic word-learning activities will be greater than for words taught without phonological-semantic word-learning activities.

\section{Method}

Ethical approval for the study was obtained from the Departmental Ethics Committee, Institute of Education, University of London. Information regarding the nature of the research, confidentiality and the right to withdraw consent at any time was provided, and informed written consent was gained from the teacher, the students' parents, and the students themselves.

\section{Participants}

All student participants attended a non-selective mainstream secondary school in the East Midlands in the UK. The Special Educational Needs Coordinator (Senco) was asked to identify a class containing students with language disorder, and a Year 9 lower ability science set was selected, comprising 9 male and 6 female students. All students in the class took part. Their chronological age range was 13:3 to 14:1 years. All students spoke English as their first language, and one spoke Spanish as an additional language. 
Only one of the participants was on a speech and language therapy caseload, and none were receiving any other speech or language intervention at the time of the study. Using the Acorn classification of socio-economic status (CACI, 2009), 40\% of the participants lived in areas categorised as 5 (hard-pressed), 33\% in category 4 (moderate means), $13 \%$ in category 3 (comfortably off), $7 \%$ in category 2 (urban prosperity), and $6 \%$ in category 1 (wealthy achievers).

\section{Assessment of language}

There were three assessment points: Time 1 (pre-intervention), Time 2 (post-

intervention, 10 weeks later), and Time 3 (follow-up, seven weeks later). The timings of the assessment points were chosen to fit in with curriculum planning and school term dates. All assessments took place individually in school.

At Time 1, information about the students' vocabulary and language ability was gained using three assessments, administered by the first author, in a one-hour session. The Receptive and Expressive One-Word Picture Vocabulary Tests (ROWPVT and EOWPVT: Brownell, 2000) were chosen as they were used in the National Health Service Trust where the first author worked. The group mean receptive and expressive vocabulary scaled scores were 7.7 (standard deviation (SD) 2.5) and 6.8 (SD 2.4) respectively. The Recalling Sentences Subtest of the Clinical Evaluation of Language Fundamentals (Semel, Wiig, and Secord, 2006) was used to gain information about the participants' overall language skills. Sentence repetition taps a range of language skills, and has been shown to be sensitive to the presence of language disorder in adolescents (Riches et al., 2010). The recalling sentences subtest group mean scaled score was 3.6 (SD 2.7). 
Science was chosen as the subject for instruction, due to the challenges science vocabulary poses for all students, and especially those with language disorder (Dockrell, Braisby, and Best, 2007). The class teacher identified 20 science curriculum key words that were going to be taught in the forthcoming term. The topic was 'Energy'. Word frequency was estimated according to frequency within the topic rather than using national corpus data, in order to be more ecologically valid. The nine energy words were identified by the teacher as being the highest frequency words within the topic: these were matched to each other as closely as possible by number of syllables, and randomly assigned to two lists. The remaining 11 words were then also matched by syllable length and randomly assigned to these two lists. (Table 1).

\section{INSERT TABLE 1 AROUND HERE}

The 20 words were placed in random order on a word knowledge assessment, adapted from Beck et al. (2002) by Elks and McLachlan (2008). On this assessment, the adult shows the student the written word, while saying it aloud, and the student assigns it a score to rate their knowledge of the word. Guidance is given by the assessor to ensure that an accurate score is assigned. A score of 1 is given if the student does not know the word; 2 if they have heard the word before but do not know what it means; 3 if they know something about what the word means but cannot use the word; and 4 if they can explain the word and use it. This method of assessment allows some insight into the student's semantic representations in a way that simple comprehension and production tasks would not (Dockrell et al., 2007). For each list of 10 words, the maximum achievable word knowledge score was therefore 40, and the minimum 10. The students completed the word knowledge assessment with an assessor who was blind to the word list status, at the start and end of the topic 'Energy', and again seven weeks later to measure retention. A protocol was followed to ensure it was administered 
consistently. Students' responses were transcribed. At each time point, transcriptions of two participants' responses $(13.3 \%)$ were marked by a second assessor, who was also blind to the list status of the words. $100 \%$ inter-rater agreement was reached through discussion.

Assessment of student and teacher views

A questionnaire, using a four point Likert scale, taking 5 - 10 minutes to complete, was given to the teacher and students at Time 2 (post-intervention). In the student questionnaire, the students were asked how helpful the phonological-semantic activities were. In the teacher questionnaire, the teacher was asked: how easy the activities were to implement; how effective the activities were; and whether the teacher would use the activities again. Both questionnaires contained questions asking whether participants would prefer vocabulary support one-to-one or in whole-class instruction, and their reasons for this. The student questionnaire was read individually to each student, and their responses were written down by the assessor with the student present.

\section{Intervention}

The first author trained the science teacher in a one-hour individual training session on the implementation of a phonological-semantic approach to vocabulary teaching using three specified word-learning activities. For the duration of the topic 'Energy', the science teacher taught the 10 experimental words using the following whole-class activities, which were aimed at reinforcing semantic and phonological knowledge of the target words. All three activities linked phonological with semantic information:

- Word map (Elks and McLachlan 2008). This was completed on the board as a whole-class activity, exploring phonological and semantic features of the word i.e. How many syllables does it have? What sound does it begin with? What 
does it rhyme with? What do you do with it? Where do you find it? What parts does it have? What group does it belong to?

- Word-wise quickie (Elks and McLachlan 2008). This was a short verbal activity of around one minute's duration to give students opportunities to think about meaning, phonological form, and usage i.e. What does it mean? What sound does it begin with? Use it in a spoken sentence.

- Sound and meaning word bingo. Students chose five words from a list on the board and wrote them in a grid. The teacher gave phonological and semantic clues, e.g. 'it begins with $\mathrm{j}$ and means the units used to measure energy' (joules), until the first student who crossed off all their words called 'Bingo'.

The specified word-learning activities were implemented in a total of nine consecutive 50-minute lessons over three weeks. A word map was completed for two words, a word-wise quickie was completed for four words, and sound and meaning word bingo, which included each word, was played four times. For control words within the same topic, the teacher taught the vocabulary according to her usual practice, which consisted of semantic activities such as word-fills, word-picture matching, word-definition matching, card-sort games, bingo using definitions only, and creating PowerPoint presentations about the topic.

The first author observed three lessons in order to monitor fidelity, frequency of word exposure, and the students' responses.

\section{Results}

Progress in word-knowledge pre-to post-intervention

Due to the small sample size, non-parametric analysis was used to analyse results. Mean word knowledge scores across time are displayed graphically in Figure 1, and the figures are reported in Table 2. 
Friedman's ANOVA indicated that there was a significant change in word knowledge over time for experimental words $\left(\chi^{2}(2)=21.396, \mathrm{p}<.001\right)$, and also for control words $\left(\chi^{2}(2)=17.640, \mathrm{p}<.001\right)$. To examine this further, a gain score was calculated by subtracting pre-intervention scores from post-intervention scores, for both experimental and control words. These were compared using the Wilcoxon Signed Ranks Test. Students made progress in both experimental and control words from pre- to postintervention, with the progress greater for the experimental words (mean gain $8.67 \mathrm{SD}$ 4.14) compared with the control words (mean gain 7.27 SD 4.56), although this difference was not significant $(Z=-1.738, p=.082)$.

\section{INSERT FIGURE 1 AROUND HERE}

\section{INSERT TABLE 2 AROUND HERE}

\section{Progress in low frequency word knowledge pre-to post-intervention}

The word lists provided by the teacher included some high frequency words such as 'sound', 'light', and 'heat'. Analysis was therefore carried out on the five lowest frequency words according to the British National Corpus (2007) (see Table 1) for the experimental and control words.

Mean low-frequency word knowledge scores across time are displayed in Figure 2, and the figures are reported in Table 3. For low-frequency words, the maximum achievable word knowledge score in each list was 20, and the minimum 5.

Friedman's ANOVA indicated that there was a significant change in low-frequency word knowledge over time for experimental words $\left(\chi^{2}(2)=25.125, \mathrm{p}<.001\right)$, and also for control words $\left(\chi^{2}(2)=23.098, \mathrm{p}<.001\right)$. The Wilcoxon Signed Ranks Test indicated that students made significantly greater progress from pre- to postintervention with low-frequency experimental words (mean gain 6.27 SD 2.69) than with low-frequency control words (mean gain 4.87 SD 2.67) $(\mathrm{Z}=-1.982, \mathrm{p}=.047)$. 


\section{INSERT FIGURE 2 AROUND HERE}

\section{INSERT TABLE 3 AROUND HERE}

\section{Maintenance}

When all ten words in each list were included in the analysis, word knowledge dropped slightly from post intervention to follow up, but this difference was not significant either for experimental words $(Z=-1.446, p=.148)$ or control words $(Z=-1.338, p=$ .181), indicating that students maintained knowledge of both sets of words. There was no difference in the degree of change between the two word lists $(Z=-.698, p=.485)$. When word knowledge of low-frequency words only was analysed, the decrease in word knowledge between post-intervention and follow-up was significant for experimental $(\mathrm{Z}=-2.401, \mathrm{p}=.016)$, but not control words $(\mathrm{Z}=-.187, \mathrm{p}=.852)$, indicating that knowledge of experimental words was not retained as well as that of the control words.

\section{Student and teacher views}

Word bingo was the most preferred activity by teacher and students alike, with $13 / 15$ of students finding it helpful. Both the teacher and six of the students liked the word-wise quickie. Ten students reported the word map to be helpful, although the teacher felt it was time-consuming, impinging on the time required for delivering the content of the syllabus. She reported that it would work better for concrete rather than abstract words. The students were asked if they would prefer to do word learning activities as a whole class in lessons, or one-to-one out of class. Nine out of 15 students felt that the best way for them to learn and remember new words would be word games as a whole class in lessons. Reasons given included having fun, not being left out, helping each other, and everyone doing the same. Four students showed a preference for one-to-one support 
outside the classroom, with three of these students saying that there would be fewer distractions, and one saying 'people don't laugh at you if you get it wrong'.

The teacher felt that whole-class word-learning activities, as well as one-to-one support, would both be effective in increasing word knowledge for students with language disorder, in addition to her current practice.

\section{Discussion}

Progress in word knowledge

Results indicate partial support for the hypothesis that increase in knowledge of experimental words would be greater than that of control words. Students made progress in both experimental and control words, with greater progress for experimental words which fell short of significance. When looking only at the low-frequency words, however, which were more technical and subject-specific, the greater progress in favour of the experimental words was significant. This is an encouraging result, bearing in mind that due to the needs of the students in this class, the teacher was already using a range of differentiation strategies. This shows the potential of what can be achieved with minimal time in collaborative planning and a small amount of direct intervention. The greater improvement in the words where phonological-semantic activities had been used corroborates the findings of previous research (Easton et al., 1997; Parsons et al., 2005; Ebbels et al., 2012; St John and Vance 2014, Wilson et al., 2015), supporting the tenet that phonological instruction can be a useful adjunct to semantic instruction, increasing the accuracy of phonological representation and strengthening the link between phonological form and meaning (Nash and Donaldson, 2005).

\section{Maintenance of word knowledge}

Maintenance for the control words appeared to be slightly stronger than for the experimental words. One possible reason for this result is that the control words were 
better known by the participants than the experimental words prior to intervention. The small drop in word knowledge for both sets of words at follow-up emphasises the importance of repetition and consolidation of new vocabulary over time.

\section{Student and teacher views}

Nine out of 15 students said they would prefer a whole-class approach rather than oneto-one vocabulary support. A narrative by two young people with language disorder (Joffe, Beverly, and Scott, 2011) makes it clear that the secondary school years were the most difficult for both of them, academically and socially. The comments made by most of students in this study bear witness to this, reflecting the positive aspects of inclusion in terms of not being left out, helping each other, and everyone doing the same. Some students did show a preference for individual vocabulary support outside the classroom, and this could be related to the ability of the students to cope with distractions and the reactions of peers. These differing views support the teacher's comment about there being a place for both in-class focussed vocabulary teaching as well as one-to-one intervention.

The teacher reported that the word map impinged on the time required for delivering the content of the syllabus. This issue could have been mitigated by more careful teacherresearcher collaboration, in order to establish how the word map could be integrated into the delivery of lesson content, for example using the semantic sections of the word map to explain the concept which was being taught.

The student and teacher comments underline variations in individual preferences, and highlight the importance of being flexible when choosing appropriate approaches to meet the needs of students and to support language learning in school.

Limitations of the study 
The small number of students, and the involvement of only one teacher, reduce generalisability to a wider population, and results therefore need to be interpreted with caution. The study needs to be replicated with a larger number of participants to increase its external validity.

One of the factors crucial to the outcomes of the experiment was the selection of the words. Words were chosen from the planned curriculum, in order to provide ecological validity; however, in reality this meant that some words were high frequency words, already known by the students; and it was not possible to control strictly for phonological structure or frequency.

These limitations illustrate some of the challenges encountered when designing a study to examine the effectiveness of interventions under real-life conditions. Nonetheless, in a field where it would be hard to recreate the laboratory conditions required for efficacy research, effectiveness research provides the best available evidence.

\section{Implications for clinical and teaching practice}

The current study took place in a mainstream secondary school with students who had language disorder, and suggests that word knowledge can be increased with little additional input, even in this older age range. The study provides a pedagogically realistic finding, showing that intervention can be successfully carried out by the teacher, in the everyday classroom context. This strengthens the case for increased speech and language therapy resources with this age group, showing that specialist support enhances the teacher's transferable knowledge and skills, and builds the capacity of the teacher to deliver 'Quality First Teaching' (DCSF, 2008). This position is supported by the findings of Starling et al. (2012); namely, that the language skills of students improved following a universal intervention based on adaptation of teacher language. 
Whole-class intervention overcomes some of the obstacles to individual support that are observed in practice, such as staffing, room availability, and withdrawal from lessons, as well as limited speech and language therapy and teaching support resources. Wholeclass intervention complies with the ideology of inclusion in terms of valuing the contribution of all students, reducing barriers to learning and participation (Booth et al., 2002), and in addition, it reaches many students and not just those individually identified. The current study has shown that providing intervention in a whole-class setting would suit those students who do not wish to be singled out, and for those who feel that the whole-class approach is fun, builds confidence, and provides opportunities to learn from each other. While a universal approach may be beneficial for all these reasons, it must be remembered that there are students who may benefit at some points from targeted or specialist intervention. Clinicians and teachers need to work in partnership to explore ways of flexibly accommodating the needs of students (Wright and Kersner, 1998). To establish how to use whole-class phonological-semantic activities as a way of delivering the content of the syllabus, it is essential to allow enough joint planning time for the teacher and speech and language therapist. Sharing the concept of curriculum-relevant therapy, in which subject syllabus content is used for therapy (Ehren, 2002), creates opportunities to combine the teacher's knowledge of the curriculum with the therapist's knowledge of word learning.

\section{Conclusion}

The current study has demonstrated the feasibility of a whole-class phonologicalsemantic approach to vocabulary teaching. Collaboration between teacher and speech and language therapist provided opportunities to share knowledge and skills, contributing to each other's continuing professional development, and facilitating the delivery of curriculum-relevant vocabulary intervention. The study needs replication on 
a larger scale to further establish the effectiveness of the intervention in enhancing the vocabulary skills not only of adolescents with language disorder, but also of typically developing adolescents. Importantly, investigation of the impact of such intervention on academic attainment is required.

\section{Acknowledgements}

Thanks go to the students, their parents, the teachers and colleagues involved in this study.

\section{Funding}

This research received no specific grant from any funding agency in the public, commercial, or not-for-profit sectors.

\section{Conflict of Interest Statement}

None declared.

\section{References}

British National Corpus XML Edition., 2007 Available at: http://www.natcorp.ox.ac.uk/ [Accessed November 6, 2015].

BECK, I., MCKEOWN, M. and KUCAN, L., 2002. Bringing Words to Life: Robust Vocabulary Instruction, New York: Guilford Publishers.

BISHOP, D. SNOWLING, M., THOMPSON, P., GREENHALGH, T., and CATALISE consortium, 2016. CATALISE: A Multinational and Multidisciplinary Delphi Consensus Study. Identifying Language Impairments in Children. PLoS ONE, 11(7).

BISHOP, D.V.M., 1997. Uncommon Understanding. , Hove: Psychology Press. 
BOLAND, L., 2009. Evaluation of a classroom based pre-teaching vocabulary intervention for school-age students with Specific Language Impairment. Unpublished MSc dissertation, London: Institute of Education.

BOOTH, T. AINSCOW, M., BLACK-HAWKINS, K., VAUGHAN, M., SHAW, L., 2002. The Index for Inclusion: Developing Learning and participation in schools, Bristol: Centre for Studies in Inclusive Education.

BROWNELL, R., 2000. Receptive and Expressive One-Word Picture Vocabulary Tests, $1^{\text {st }}$ Edition. Academic Therapy Publications

CAIN, K., OAKHILL, J. V and LEMMON, K., 2004. Individual differences in the inference of word meanings from context: the influence of reading comprehension, vocabulary knowledge, and memory capacity. Journal of Educational Psychology, 96(4), pp.671-681.

CLARK, E., 1995. Later Lexical Development and Word Formation. In P. Fletcher and B. MacWhinney (eds.), The Handbook of Child Language. Oxford: Blackwell, pp. 293312.

CLEGG, J., HOLLIS, C., MAWHOOD, L., and RUTTER, M. 2005. Developmental language disorders a follow-up in later adult life. Cognitive, language and psychosocial outcomes. Journal of Child Psychology and Psychiatry, 46(2), pp.128-149.

CROLL, P., 1995. Early Linguistic Attainment, Family Background and Performance in 16 + Examinations. Educational Studies Vol 21(1) p13-28, 21(1), pp.13-28.

DEPARTMENT FOR CHILDREN SCHOOLS AND FAMILIES, 2008. Personalised Learning: A Practical Guide., DCSF Publications.

DEPARTMENT FOR EDUCATION. (2014). The national curriculum in England Key stages 3 and 4 framework document. UK: Department for Education. 
DOCKRELL, J.E., BRAISBY, N. and BEST, R.M., 2007. Children's acquisition of science terms: Simple exposure is insufficient. Learning and Instruction, 17(6), pp.577594.

EASTON, C., SHEACH, S. and EASTON, S., 1997. Teaching vocabulary to children with wordfinding impairment using a combined semantic and phonological approach: an efficacy study. Child Language Teaching and Therapy, 13, pp.125-142.

EBBELS, S., NICOLL, H., and CLARK, B. 2012. Effectiveness of semantic therapy for word-finding difficulties in pupils with persistent language impairments: a randomized control trial. International Journal of Language and Communication Disorders, 47(1), pp.35-51.

EHREN, B., 2002. Speech-Language Pathologists Contributing Significantly to the Academic Success of High School Students: A Vision for Professional Growth. Topics in Language Disorders, 22(2), pp.60-80.

ELKS, L. and MCLACHLAN, H., 2008. Secondary Language Builders: Speech and Language Support for $11-16 s$, St Mabyn: Elklan.

JOFFE, V. L., 2011. Vocabulary Enrichment Programme, London: Speechmark Publishers.

JOFFE, V.L., BEVERLY, A. and SCOTT, L., 2011. My Speech, Language and Communication: A real kind of overwhelming kind of challenge sometime. In K. Hilari and N. Botting (eds.), The Impact of Communication Disability Across the Lifespan. Guildford: J and R Press.

JOFFE, V., RIXON, L., HIRANI, S., and HULME, C. (forthcoming). Improving storytelling and vocabulary in secondary school students with language and communication difficulties: A randomized control intervention study. 
JOHNSON, C. J., BEITCHMAN, J. H., and BROWNLIE, E. B. (2010). Twenty-Year Follow-Up of Children With and Without Speech-Language Impairments: Family, Educational, Occupational, and Quality of Life Outcomes. American Journal of Speech Language Pathology, 19, 51-65.

KLINGNER, J., VAUGHN, S., SCHUMM, J., COHEN, P and FORGAN, J., 1998. Inclusion or pull-out: Which do students prefer? . Journal of Learning Disabilities, 31(2), p.148.

LAHEY, M. and EDWARDS, J., 1999. Why do children with specific language impairment name pictures more slowly than their peers? Journal of Speech and Hearing Research, 39(5), p.1081.

LAWRENCE, J., CAPOTOSTO, L., BRANUM-MARTIN, L., WHITE, C., and SNOW, C., 2012. Language proficiency, home-language status, and English vocabulary development: A longitudinal follow-up of the Word Generation program. BilingualismLanguage and Cognition, 15(3), pp.437-451.

LEONARD, L. (1998). Children with Specific Language Impairment. Cambridge, MA: The MIT Press.

LESAUX, N., KIEFFER, M., KELLEY, J., and HARRIS, J. 2014. Effects of Academic Vocabulary Instruction for Linguistically Diverse Adolescents: Evidence From a Randomized Field Trial. American Educational Research Journal, 51(6), pp.11591194.

MCGREGOR, K., OLESON, J., BAHNSEN, A., \& DUFF, D. (2013). Children with developmental language impairment have vocabulary deficits characterized by limited breadth and depth. International Journal of Language \& Communication Disorders, 48(3), 307-319. https://doi.org/10.1111/1460-6984.12008 
NASH, M. and DONALDSON, M.L., 2005. Word Learning in Children With Vocabulary Deficits. Journal of Speech, Language and Hearing Research, 48(2), pp.439-458.

NIPPOLD, M.A., 2007. Later language development: School-age children, adolescents, and young adults 3rd ed., Austin, TX: Pro-Ed.

NORBURY, C., GOOCH, D., WRAY, C., BAIRD, G., CHARMAN, T., SIMONOFF, E., VAMVAKAS, G. and PICKLES, A., 2016. The impact of nonverbal ability on prevalence and clinical presentation of language disorder: evidence from a population study. Journal of Child Psychology and Psychiatry 57(11), pp. 1247-1257

PARSONS, S., LAW, J. and GASCOIGNE, M., 2005. Teaching receptive vocabulary to children with specific language impairment:a curriculum-based approach. . Child Language Teaching and Therapy, 21(1), pp.39-59.

RICHES, N., LOUCAS, T., BAIRD, G., CHARMAN, T., and SIMONOFF, E. 2010. Sentence repetition in adolescents with specific language impairments and autism: an investigation of complex syntax. International Journal of Language and Communication Disorders, 45(1), pp.47-60.

SEMEL, E., WIIG, E. and SECORD, W.A., 2006. Clinical evaluation of language fundamentals UK 4th edition.

SNOWLING, M. J., ADAMS, J. W., BISHOP, D. V. M., and STOTHARD, S. E. (2001). Educational attainments of school leavers with a preschool history of speechlanguage impairments. International Journal of Language and Communication Disorders, 36(2), 173-183.

SNOWLING, M. J., MUTER, V., \& CARROLL, J. M. (2007). Children at family risk of dyslexia: A follow-up in adolescence. Journal of Child Psychology and Psychiatry, $48,609-618$. 
ST. JOHN, P. and VANCE, M., 2014. Evaluation of a principled approach to vocabulary learning in mainstream classes. Child Language Teaching and Therapy, 30(3), pp.255-271.

STARLING, J., MUNRO, N., TOGHER, L., and ARCIULI, J., 2012.. Training Secondary School Teachers in Instructional Language Modification Techniques to Support Adolescents With Language Impairment: A Randomized Controlled Trial. Language, Speech and Hearing Services in Schools, 43(4), pp.474-495.

WHITMIRE, K., 2000. Adolescence as a Developmental Phase: A Tutorial. Topics in Language Disorders, 20(2), pp.1-14.

WILSON, J. ALDERSLEY, A., DOBSON, C., EDGAR, S., HARDING, C., LUCKINS, J., and WISEMAN, F., 2015. The effectiveness of semantic therapy for the word finding difficulties of children with severe and complex speech, language and communication needs. Child Language Teaching and Therapy, 31(1), pp.7-17. WRIGHT, J. and KERSNER, M., 1998. Supporting Children with Communication Problems: Sharing the Workload, London: David Fulton Publishers. 
Table 1. Word Lists

\begin{tabular}{|c|c|c|c|}
\hline & & $\begin{array}{l}\text { Syllable } \\
\text { length }\end{array}$ & $\begin{array}{l}\text { Frequency in } \\
\text { the British } \\
\text { National } \\
\text { Corpus } X M L \\
\text { Edition } \\
\text { (2007) }\end{array}$ \\
\hline \multirow{11}{*}{$\begin{array}{l}\text { Experimental words taught } \\
\text { using phonological-semantic } \\
\text { strategies }\end{array}$} & sound & 1 & 13904 \\
\hline & light & 1 & 22544 \\
\hline & joules & 1 & 15 \\
\hline & sources & 2 & 6578 \\
\hline & transferred & 2 & 3165 \\
\hline & nuclear & 3 & 8135 \\
\hline & generator & 4 & 444 \\
\hline & Sankey diagram & 5 & 0 \\
\hline & elastic potential & 6 & 1 \\
\hline & hydroelectricity & 7 & 10 \\
\hline & & Mean 3.2 & Mean 5479.6 \\
\hline \multirow{11}{*}{$\begin{array}{l}\text { Control words taught using } \\
\text { routine teaching strategies }\end{array}$} & heat & 1 & 5781 \\
\hline & fuels & 1 & 581 \\
\hline & solar & 2 & 1316 \\
\hline & turbine & 2 & 255 \\
\hline & chemical & 3 & 4449 \\
\hline & kinetic & 3 & 223 \\
\hline & conservation & 4 & 3966 \\
\hline & electrical & 4 & 2265 \\
\hline & renewable & 4 & 334 \\
\hline & gravitational potential & 8 & 22 \\
\hline & & Mean 3.2 & Mean 1919.2 \\
\hline
\end{tabular}


Table 2. Mean word-knowledge scores across time

\begin{tabular}{|c|c|c|c|c|}
\hline & Time 1 & Time 2 & Time 3 & \\
\hline & $\begin{array}{c}\text { Pre } \\
\text { intervention } \\
(\mathrm{N}=15) \\
\text { Mean }(\mathrm{SD})\end{array}$ & $\begin{array}{c}\text { Post } \\
\text { intervention } \\
(\mathrm{N}=15) \\
\text { Mean (SD) }\end{array}$ & $\begin{array}{l}\text { Follow-up } \\
(\mathrm{N}=14) \\
\text { Mean (SD) }\end{array}$ & $\begin{array}{l}\text { Increase in } \\
\text { word } \\
\text { knowledge } \\
\text { pre - post } \\
\text { intervention }\end{array}$ \\
\hline $\begin{array}{l}\text { Experimental } \\
\text { words }\end{array}$ & $19.00(3.80)$ & $27.67(5.47)$ & $26.36(6.153)$ & $8.67(4.14)$ \\
\hline Control words & $21.13(5.67)$ & $28.40(5.85)$ & $27.07(5.413)$ & $7.27(4.56)$ \\
\hline
\end{tabular}

$\mathrm{SD}=$ Standard Deviation

Experimental words: taught using specified phonological-semantic word-learning activities

Control words: taught without using the specified activities 
Table 3: Mean word-knowledge scores for low-frequency words across time.

\begin{tabular}{|c|c|c|c|c|}
\hline & Time 1 & Time 2 & Time 3 & \\
\hline & $\begin{array}{c}\text { Pre } \\
\text { intervention } \\
(\mathrm{N}=15) \\
\text { Mean (SD) }\end{array}$ & $\begin{array}{c}\text { Post } \\
\text { intervention } \\
(\mathrm{N}=15) \\
\text { Mean (SD) }\end{array}$ & $\begin{array}{l}\text { Follow-up } \\
(\mathrm{N}=14) \\
\text { Mean (SD) }\end{array}$ & $\begin{array}{l}\text { Increase in } \\
\text { word } \\
\text { knowledge } \\
\text { pre - post } \\
\text { intervention }\end{array}$ \\
\hline $\begin{array}{l}\text { Experimental } \\
\text { low-frequency } \\
\text { words }\end{array}$ & $7.40(2.10)$ & $13.67(3.11)$ & $12.43(2.74)$ & $6.27(2.69)$ \\
\hline $\begin{array}{l}\text { Control low- } \\
\text { frequency } \\
\text { words }\end{array}$ & $9.80(3.23)$ & $14.67(3.22)$ & $14.50(3.18)$ & $4.87(2.67)$ \\
\hline
\end{tabular}

Experimental words: taught using specified phonological-semantic word-learning activities

Control words: taught without using the specified activities 
Figure 1. Mean word-knowledge scores across time.

Figure 2. Mean low-frequency word-knowledge scores across time. 